\title{
The Promise of Percutaneous Transhepatic Variceal Embolization for Both Gastroesophageal and Ectopic Varices-An Australian Case Series
}

\author{
Chaitanya Ambati ${ }^{1, \odot ~ M a r k ~ D a n t a ~}{ }^{2} \quad$ David Boshell $^{1} \quad$ Jesse Ende ${ }^{1} \quad$ David Williams $^{2} \quad$ Joga Chaganti ${ }^{1, \odot}$ \\ ${ }^{1}$ Department of Medical Imaging, St Vincent's Hospital, Sydney, \\ Australia \\ 2Department of Gastroenterology, St Vincent's Hospital, Sydney, \\ Australia \\ Address for correspondence Joga Chaganti, MD, FRANZCR, \\ Department of Medical Imaging, St Vincent's Hospital, 390 Victoria, \\ Street, Darlinghurst, NSW, 2010, Australia \\ (e-mail: joga.chaganti@svha.org.au).
}

J Clin Interv Radiol ISVIR:2021;5:3-10

\begin{abstract}
Purpose This article aims to report Australian experience of percutaneous transhepatic embolization of gastroesophageal and ectopic varices.

Method Eight consecutive patients (mean age 61.8 years, 7 men) who had undergone percutaneous transhepatic variceal embolization (PTVE) for variceal bleeding between October 2013 and February 2020 were analyzed. All patients were admitted from the emergency department. The following embolic materials were used-coils, Onyx 18 (Medtronic), and n-butyl cyanoacrylate plus lipiodol.

Results Post-PTVE, all eight patients demonstrated clinical and radiological improvement in the immediate postprocedure period ( $<24$ hours). Patients were followed for a mean of $44 \pm 24$ days postprocedure. Two patients were lost to follow-up. The postprocedure complications included rebleeding $(n=1)$, hepatic encephalopathy $(n=1)$, hemoperitoneum $(n=1)$, ileus $(n=1)$, and abdominal pain $(n=3)$.

Keywords

- portal hypertension

- transhepatic

- embolization

Conclusion PTVE is an effective treatment option for patients with uncontrolled variceal bleeding (ectopic as well as gastroesophageal) especially when the traditional therapies such as transjugular intrahepatic portosystemic shunts, endoscopic variceal ligation, and balloon-occluded retrograde transvenous obliteration are contraindicated or ineffective.
\end{abstract}

\section{Introduction}

Variceal bleeding is a serious complication of portal hypertension and a leading cause of death in patients with liver cirrhosis. Gastroesophageal varices are present in approximately $50 \%$ of patients with cirrhosis and their presence correlates with severity of liver disease. ${ }^{1}$ Endoscopic variceal ligation (EVL) is considered the endoscopic treatment of choice for esophageal variceal bleeding; however, treatment failure with this regime occurs in approximately 10 to $15 \%$ of patients. ${ }^{2}$ Furthermore, EVL cannot be performed on patients with ectopic varices, such as ileal or anorectal. In such cases and in those with advanced cirrhosis where recurrent variceal bleeding is a problem, ${ }^{3-5}$ transjugular intrahepatic portosystemic shunt (TIPS) has emerged as a superior alternative to EVL over the past two decades. ${ }^{6,7}$ However, TIPS is not without its own complications such as stent occlusion and an increased risk of hepatic encephalopathy (HE). ${ }^{8,9}$ Balloon-occluded retrograde transvenous obliteration (BRTO) is another option and is a popular treatment for gastric varices in Japan. ${ }^{10}$ However, it cannot be performed
DOI https://doi.org/ $10.1055 / \mathrm{s}-0041-1723061$ ISSN 2457-0214.

\footnotetext{
(C) 2021. Indian Society of Vascular and Interventional Radiology. This is an open access article published by Thieme under the terms of the Creative Commons Attribution-NonDerivative-NonCommercial-License, permitting copying and reproduction so long as the original work is given appropriate credit. Contents may not be used for commercial purposes, or adapted, remixed, transformed or built upon. (https://creativecommons.org/licenses/by-nc-nd/4.0/).

Thieme Medical and Scientific Publishers Pvt. Ltd. A-12, 2nd Floor, Sector 2, Noida-201301 UP, India
} 
in patients without catheterizable gastrorenal shunts. In such patients, percutaneous transhepatic variceal embolization (PTVE) can still be used and has shown satisfactory results. ${ }^{11,12}$

PTVE is an alternative technique to manage both gastroesophageal and ectopic variceal bleeding that was first described in 1974. ${ }^{13}$ Although reports confirmed its efficacy in controlling bleeding in approximately 70 to $90 \%{ }^{14-17}$ of patients, it has not gained widespread adoption as the procedure was initially complicated by variceal recurrence and rebleeding in approximately 37 to $65 \%$ of patients within a few months after PTVE. ${ }^{14,18,19}$ However, the development of newer embolic materials have led to numerous reports on the successful use of PTVE in the management of uncontrolled variceal bleeding secondary to cirrhotic portal hypertension. We report our experience of PTVE in patients with both gastroesophageal and ectopic variceal bleeding.

\section{Method}

A search of the St Vincent's Public Hospital (Sydney, NSW, Australia) record databases identified eight patients who underwent PTVE between October 2013 and February 2020 and were included in this study. One patient who underwent an attempted PTVE was also identified but was excluded from this study as no embolization was performed. This case series meets the requirements of the National Statement on Ethical Conduct in Human Research as approved by St Vincent's Hospital Human Research Ethics Committee (reference LNR/17/SVH/173).

Patient symptoms ranged from typically large volume hematemesis to melena, hypotension, and tachycardia. All patients had cirrhosis and portal hypertension. Only one patient (case 3 ) had features of HE. All patients received octreotide and pantoprazole infusions, packed red blood cell transfusions, and intravenous fluids before undergoing any endoscopic or radiological interventions.

Inclusion criteria for PTVE were as follows: (1) cirrhosis confirmed on imaging and laboratory examinations, (2) variceal bleeding not controlled by EVL or rebleeding occurred after EVL, and (3) patent portal vein identified on preoperative imaging. Exclusion criteria were: (1) coronary artery disease, cardiopulmonary insufficiency, or severe hypertension; (2) portal vein thrombosis; and (3) concomitant hepatocellular carcinoma or other malignancy.

Five patients (cases 1, 2, 3, 7, and 8) underwent EVL or attempted EVL as a first line procedure. All patients had abdominal sonograms prior to the procedure and four patients $(5,6,7$, and 8$)$ also had recent multiphase computed tomography (CT) imaging (within 6 weeks of the procedure). Patients were promptly transferred to the angiography suite once uncontrolled bleeding was recognized, which we defined as hematemesis, melena, or bleeding from ectopic sites (e.g., umbilical varices) with no other potential source of bleeding identified (such as an ulcer). After discharge, patients were given instructions for outpatient clinic follow-up with their treating gastroenterologist in 4 to 6 weeks. Cases 2 and 8 also had endoscopy at follow-up.

\section{PTVE Procedure and Materials}

PTVE was performed in the angiographic suite at St Vincent's Public Hospital, Darlinghurst, by one of two fellowship-trained interventional radiologists with more 30 years cumulative experience. Typically, intrahepatic portal venous access was acquired via transhepatic puncture under either sonographic or fluoroscopic guidance using a 4-F Neff (Cook Medical Systems) percutaneous access set. A 6-F working sheath was then introduced followed by portal venography to evaluate the index varices as well as the feeding vessels and draining veins.

The main feeding vessels (for example, coronary, splenic, and superior and inferior mesenteric veins) and index varices were selectively and superselectively catheterized. Typically, a directional catheter (Van Schie, Cook Medical Systems) was used to access the coronary and short gastric vein collaterals and a straight 4-F Glidecath (Terumo) was used to access mesenteric and umbilical veins. Embolization was typically performed with a 2.7-F, 110-cm microcatheter (Progreat, Terumo) and a variety of embolic agents were used including coils, Onyx 18 (Medtronic), and n-butyl cyanoacrylate (NBCA) plus lipiodol. Onyx 18 is the trade name for a liquid embolic agent consisting of ethylene vinyl alcohol copolymer (6\%), soluted in dimethyl sulfoxide. Next, portal venography was performed to assess the extent of variceal obliteration. If other feeding vessels were identified, further embolization was performed until complete variceal obliteration was achieved. After angiographic confirmation of successful variceal obliteration, the 6-F sheath was removed and the puncture tract was sealed with a Gelfoam (Pfizer) slurry.

Clinical success was determined as initial hemostasis in the immediate postoperative period ( $<24$ hours), determined by absence of hematemesis, melena, or hematochezia. Technical success was determined at the end of the procedure by demonstrating variceal obliteration by angiography. We defined rebleeding as the presence of hematemesis, melena, or bleeding from ectopic sites (e.g., umbilical varices). Data was analyzed and graphs were made using IBM SPSS Statistics 26.0 (IBM Corp.).

\section{Results}

\section{Demographics and Follow-Up}

The mean age was $61.8 \pm 16.3$ years and only one patient was female. Preprocedure Model for End-Stage Liver Disease (MELD) scores were retrospectively calculated and had a mean of $17 \pm 5$. Response to PTVE was confirmed initially angiographically and later clinically in the immediate ( $<24$ hours) postoperative period. All eight cases showed a good angiographic result with initial clinical hemostasis achieved in $100 \%$ of cases (-Tables 1 and 2 ). One patient (case 3 ) had an episode of rebleeding (melena) 6 days after PTVE (while still an inpatient), for which adjunctive EVL was performed to good effect. However, after discharge from hospital, none had rebleeding when assessed at their routine short-term outpatient clinic follow-up at a mean of $44 \pm$ 24 days postprocedure (range 18-77). Although there was no evidence of rebleeding, adjunctive EVL was also attempted 
Table 1 Details of patients

\begin{tabular}{|c|c|c|c|c|c|c|c|c|c|}
\hline Case & Age & Sex & $\begin{array}{l}\text { Primary } \\
\text { diagnosis }\end{array}$ & $\begin{array}{l}\text { MELD } \\
\text { score }\end{array}$ & Symptoms & Site & $\begin{array}{l}\text { Other } \\
\text { treatments }\end{array}$ & $\begin{array}{l}\text { Date of } \\
\text { PTVE }\end{array}$ & $\begin{array}{l}\text { Follow-up } \\
\text { (d) }\end{array}$ \\
\hline 1 & 43 & $\mathrm{M}$ & Alcoholic cirrhosis & 15 & $\begin{array}{l}\text { Large volume } \\
\text { hematemesis }\end{array}$ & Esophageal & Attempted EVL & $\begin{array}{l}\text { October 2, } \\
2013\end{array}$ & 69 \\
\hline 2 & 50 & $\mathrm{M}$ & $\begin{array}{l}\text { Cirrhosis secondary } \\
\text { to hepatitis B }\end{array}$ & 19 & $\begin{array}{l}2 \mathrm{~d} \text { of } \\
\text { hematemesis and } \\
\text { melena }\end{array}$ & Esophageal & $\begin{array}{l}\text { EVL } 2 \text { y prior } \\
\text { as primary } \\
\text { prophylaxis and } \\
\text { attempted EVL } \\
\text { at presentation }\end{array}$ & $\begin{array}{l}\text { February } \\
24,2014\end{array}$ & 21 \\
\hline 3 & 50 & $M$ & Alcoholic cirrhosis & 12 & $\begin{array}{l}\text { Hematemesis } \\
\text { and hepatic } \\
\text { encephalopathy }\end{array}$ & Esophageal & $\begin{array}{l}\text { EVL } 3 \text { wk prior } \\
\text { followed by } \\
\text { failed TIPS }\end{array}$ & $\begin{array}{l}\text { July } 30 \\
2014\end{array}$ & 77 \\
\hline 4 & 93 & $\mathrm{~F}$ & $\begin{array}{l}\text { Primary biliary } \\
\text { cirrhosis }\end{array}$ & 16 & Per-rectal bleed & Rectal & $\begin{array}{l}\text { Previously } \\
\text { failed surgical } \\
\text { management } \\
\text { of hemorrhoids }\end{array}$ & $\begin{array}{l}\text { August 12, } \\
2015\end{array}$ & 37 \\
\hline 5 & 64 & M & Alcoholic cirrhosis & 12 & Per-rectal bleed & Ileal & $\mathrm{Nil}$ & $\begin{array}{l}\text { June } 25, \\
2014\end{array}$ & - \\
\hline 6 & 60 & $M$ & $\begin{array}{l}\text { Cirrhosis second- } \\
\text { ary to alcohol and } \\
\text { hepatitis C }\end{array}$ & 14 & $\begin{array}{l}\text { Bleeding from } \\
\text { umbilical varices }\end{array}$ & Umbilical & Nil & $\begin{array}{l}\text { May 16, } \\
2018\end{array}$ & - \\
\hline 7 & 78 & $M$ & $\begin{array}{l}\text { Nonalcoholic } \\
\text { steatohepatitis } \\
\text { cirrhosis }\end{array}$ & 21 & Hematemesis & $\begin{array}{l}\text { Gastric } \\
\text { fundal and } \\
\text { esophageal }\end{array}$ & Attempted EVL & $\begin{array}{l}\text { November } \\
2,2018\end{array}$ & 39 \\
\hline 8 & 48 & $M$ & Alcoholic cirrhosis & 27 & $\begin{array}{l}\text { Hematemesis and } \\
\text { melena }\end{array}$ & Esophageal & $\begin{array}{l}\text { Failed EVL } 2 \text { wk } \\
\text { prior (bands } \\
\text { dislodged) }\end{array}$ & $\begin{array}{l}\text { November } \\
22,2018\end{array}$ & 18 \\
\hline
\end{tabular}

Abbreviations: EVL, endoscopic variceal ligation; MELD, Model for End-Stage Liver Disease; PTVE, percutaneous transhepatic variceal embolization; TIPS, transjugular intrahepatic portosystemic shunts.

Table 2 Treatment details and complications

\begin{tabular}{|c|c|c|c|c|c|}
\hline Case & Treatment & $\begin{array}{l}\text { Treatment } \\
\text { details }\end{array}$ & $\begin{array}{l}\text { Procedure-related } \\
\text { complications }\end{array}$ & $\begin{array}{l}\text { Complications due } \\
\text { to underlying liver } \\
\text { pathology }\end{array}$ & $\begin{array}{l}\text { Management of } \\
\text { complications }\end{array}$ \\
\hline 1 & Onyx 18 & $10.5 \mathrm{~mL}$ (7 vials) & $\begin{array}{l}\text { Clinically insignificant } \\
\text { portal vein thrombus and } \\
\text { ileus }\end{array}$ & $\mathrm{Nil}$ & Conservative \\
\hline 2 & NBCA & $\begin{array}{l}6 \mathrm{~mL} \text { diluted } \\
\text { to } 60 \% \text { with } \\
\text { lipiodol }\end{array}$ & Nil & $\begin{array}{l}\text { Abdominal pain (from } \\
\text { ascites) and right pleural } \\
\text { effusion (nonbilious) }\end{array}$ & $\begin{array}{l}\text { Paracentesis and } \\
\text { thoracentesis }\end{array}$ \\
\hline 3 & Onyx 18 & $9 \mathrm{~mL}$ (6 vials) & $\begin{array}{l}\text { Small volume } \\
\text { hemoperitoneum }\end{array}$ & $\begin{array}{l}\text { Rebleeding presenting as } \\
\text { melena ( } 6 \mathrm{~d} \text { post-PTVE) }\end{array}$ & $\begin{array}{l}\text { EVL for rebleeding; } \\
\text { Conservative management } \\
\text { for minor hemoperitoneum }\end{array}$ \\
\hline 4 & $\begin{array}{l}\text { Nester coils and } \\
\text { NBCA }\end{array}$ & $\begin{array}{l}5 \mathrm{~mL} \mathrm{NBCA} \\
\text { diluted to } 50 \% \\
\text { and coils } 8 \mathrm{~cm} \times \\
3-11 \mathrm{~mm}\end{array}$ & Nil & $\begin{array}{l}\text { Abdominal pain (from } \\
\text { ascites) }\end{array}$ & Paracentesis \\
\hline 5 & Onyx 18 & $4.5 \mathrm{~mL}$ (3 vials) & Nil & $\begin{array}{l}\text { Nil reported (lost to } \\
\text { follow-up) }\end{array}$ & - \\
\hline 6 & NBCA & $\begin{array}{l}6 \mathrm{~mL} \text { diluted } \\
\text { to } 60 \% \text { with } \\
\text { lipiodol }\end{array}$ & Nil & $\begin{array}{l}\text { Nil reported (lost to } \\
\text { follow-up) }\end{array}$ & - \\
\hline 7 & NBCA & $\begin{array}{l}8 \mathrm{~mL} \text { diluted } \\
\text { to } 40 \% \text { with } \\
\text { lipiodol }\end{array}$ & $\begin{array}{l}\text { Clinically insignificant } \\
\text { nontarget pulmonary } \\
\text { embolization }\end{array}$ & Hepatic encephalopathy & $\begin{array}{l}3 \mathrm{~d} \text { of } 2 \text {-hourly } 30-\mathrm{mL} \\
\text { lactulose }\end{array}$ \\
\hline 8 & $\begin{array}{l}\text { Nester coils and } \\
\text { NBCA }\end{array}$ & $\begin{array}{l}5 \mathrm{~mL} \text { diluted } \\
\text { to } 50 \% \text { with } \\
\text { lipiodol and coils } \\
7 \mathrm{~cm} \times 3 \mathrm{~mm}\end{array}$ & Nil & $\begin{array}{l}\text { Abdominal pain (from } \\
\text { ascites) }\end{array}$ & Paracentesis \\
\hline
\end{tabular}

Abbreviations: EVL, endoscopic variceal ligation; NBCA, n-butyl cyanoacrylate; PTVE, percutaneous transhepatic variceal embolization. 
in case 2 ( 3 weeks post-PTVE) as prophylaxis and due to an initial failed EVL attempt. However, banding was postponed due to large volume food residue. Cases 5 and 6 were lost to follow-up.

During long-term follow-up, none of our patients represented to the emergency department or outpatient clinic with rebleeding at 1 year postprocedure. At 2 years, however, there was one fatality (case 7 ) at 475 days postprocedure and one patient (case 3 ) presented with rebleeding at 412 days postprocedure, which was treated with EVL. At 3 years, there were no new deaths or cases of rebleeding. Excluding cases immediately

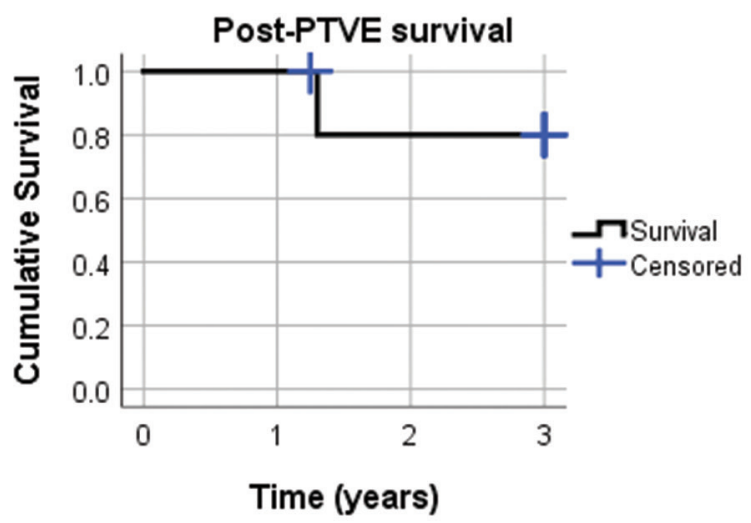

Fig. 1 Cumulative survival post-percutaneous transhepatic variceal embolization (PTVE).

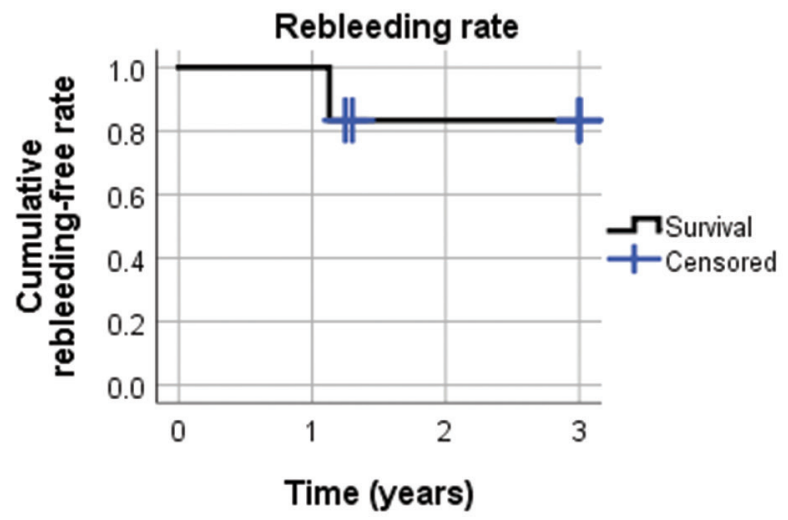

Fig. 2 Cumulative rebleeding-free rate post-percutaneous transhepatic variceal embolization (PTVE).
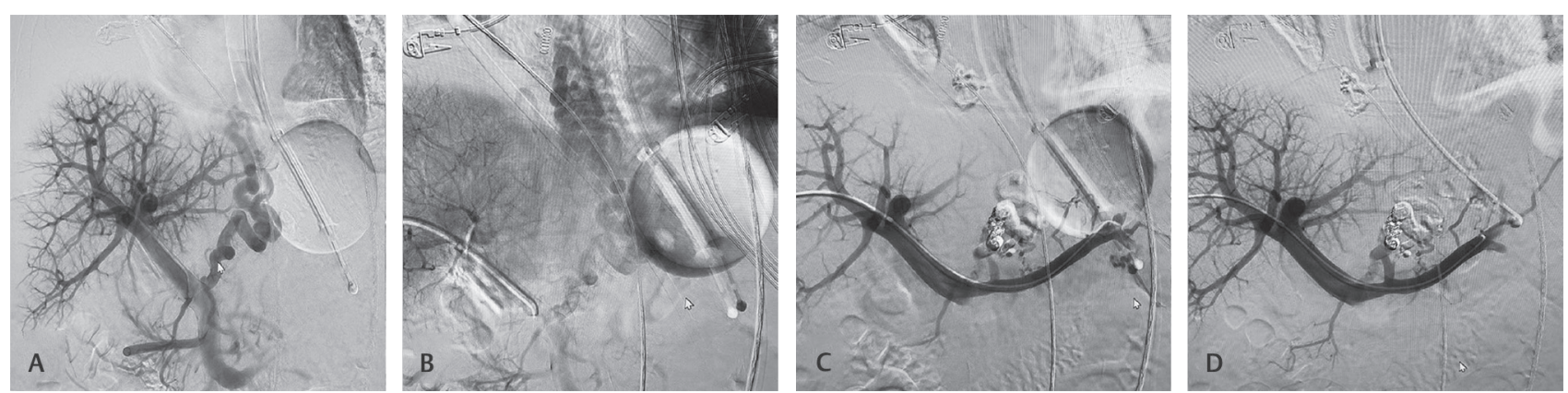

Fig. 3 Portal venography depicting: (A and B) Large gastroesophageal varices from the coronary vein; (C and D) Postembolization portography. Note deflation of Sengstaken-Blakemore tube in D. lost to follow-up, cumulative survival and rebleeding-free rates were calculated using the Kaplan-Meier method and charted (-Figs. 1 and 2). Over 3 years, mean survival was 2.66 years (95\% confidence interval [CI]: 2.07-3.23) and mean time before rebleeding was 2.69 years (95\% CI: 2.13-3.25).

\section{Cases of Gastroesophageal Varices}

Five of our cases $(1,2,3,7$, and 8$)$ presented with gastroesophageal variceal bleeding. All five cases showed complete variceal obliteration as determined by postembolization portal venography and there were no immediate postprocedural complications ( - Tables 1 and $\mathbf{2}$ ). Only case 2 presented with large volume ascites that required drainage (using 10-F and 12-F multipurpose catheters) prior to PTVE. A total of 4 $\mathrm{L}$ was drained throughout the procedure. Case 3 was technically difficult and required multiple punctures to successfully access the portal vein. For case 8, we demonstrated successful variceal obliteration after deflating a SengstakenBlakemore tube (inserted preprocedure) on postprocedure portal venography (-Fig. 3 ).

\section{Cases of Ectopic Varices}

Three of our cases $(4,5$, and 6$)$ presented with ectopic variceal bleeding (-Tables 1 and 2). All three cases showed complete variceal obliteration as determined by postembolization venography. Case 4 demonstrated a normal variant on portomesenteric venography where the inferior mesenteric vein drained into the superior mesenteric vein. Furthermore, we used both coils and NBCA to embolize varices encircling the lower anus ( - Fig. 4 ). Case 5 presented with pelvic ileal varices ( $\mathbf{- F i g . 5 A}$ ) from the superior mesenteric vein draining into the right internal iliac vein. 5-F sheaths were also inserted into the left femoral artery and vein to exclude a preprocedure clinical suspicion of an arteriovenous malformation. Case 6 presented with bleeding from an umbilical hernia site from varices arising from a recanalized umbilical vein, which was successfully embolized along with incidental gastroesophageal varices from the coronary vein.

\section{Complications}

We experienced no significant complications during the procedure itself; however, several cases had postprocedure complications (-Table 2 ). Case 1 had a small thrombus at the origin of the main portal vein, which was identified on 
a multiphase CT performed 6 days after the procedure for abdominal distension and dilated bowel loops seen on a plain radiograph (diagnosed as ileus). In addition to the rebleeding experienced 6 days post-PTVE in case 3, there was also minor perihepatic contrast extravasation and small volume hemoperitoneum seen on a multiphase CT performed 7 hours postprocedure with a decrease in hemoglobin by $5 \mathrm{~g} / \mathrm{L}$. This complication likely occurred as a result of the multiple unsuccessful punctures made due to technical difficulty. Case 6 had a small amount of nontarget embolization to the lungs, which was diagnosed fluoroscopically at the time of the procedure. None of our cases experienced bowel ischemia or bile leak. Cases 2, 4, and 8 all experienced abdominal distension and pain from ultrasound-proven ascites that required inpatient paracentesis for symptomatic relief. Case 2 also developed a large right pleural effusion (nonbilious), which was percutaneously drained without complication. Case 7 developed grade 4 (West Haven criteria) HE lasting 3 days, managed with 2 hourly 30-mL lactulose.

\section{Discussion}

Although introduced over four decades ago, recent advances in radiological techniques and modern embolic agents have led us to explore the use of PTVE as a treatment for uncontrolled variceal hemorrhage. Following an episode of acute variceal bleeding, patients with cirrhosis are at a high risk of recurrent bleeding and increased mortality. ${ }^{20}$ However, PTVE has been shown to be an effective and safe method for
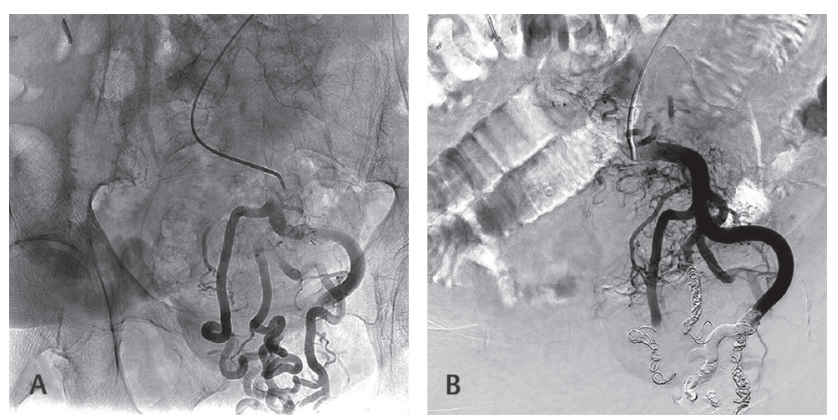

Fig. 4 Portal venography depicting: (A) Rectal varices from the inferior mesenteric vein; (B) Postembolization state with coils and n-butyl cyanoacrylate. preventing these complications. ${ }^{21}$ Our suggested approach to a patient presenting with variceal bleeding is shown in -Fig. 6.

\section{Esophageal Varices}

Esophageal varices result from portal hypertension leading to the formation of portosystemic collateral vessels. These typically occur at the junction of the coronary vein and short gastric veins (portal circulation) and the distal esophageal veins related to the azygos vein (systemic circulation). Esophageal veins are located within the lower esophageal wall, while paraesophageal and periesophageal veins are situated outside of the lower esophageal wall. ${ }^{21}$ The coronary (left gastric) vein, which divides into anterior and posterior branches, supplies these vessels. Specifically, the anterior branch supplies the esophageal veins and the posterior branch forms the para- and periesophageal veins. The incidence of severe para- and periesophageal collateral veins is high in recurrent varices, and as a result, the embolization of these feeding vessels is as important as the esophageal veins. ${ }^{22}$

\section{Gastric Varices}

Gastric varices are less prevalent and less likely to bleed than esophageal varices; however, when bleeding does occur, they are associated with higher mortality ${ }^{23-25}$ and where endoscopic treatment has shown limited longterm success. ${ }^{26}$ As described earlier, BRTO is a widely used, successful, and accepted treatment of gastric varices in Japan. ${ }^{10} \mathrm{~A}$ variation of BRTO in the form of vascular plug-assisted retrograde transvenous obliteration (PARTO) is gaining popularity as it is technically easier to perform, avoids many shortcomings of BRTO, and has shown greater success rates for treating refractory HE and gastric variceal bleeding. ${ }^{27,28}$ However, neither BRTO or PARTO can be performed if patients do not have a catheterizable gastrorenal shunt. ${ }^{29,30}$ Furthermore, there are only a few scattered case reports on the use of BRTO for ectopic varices, ${ }^{31-36}$ none of which include rectal varices. For these patients, PTVE can still be performed. ${ }^{11,12}$ We successfully used PTVE to treat case 7 , where a large gastric varix ( - Fig. 7 ) seen on CT was also identified by endoscopy but deemed unsuitable for treatment.
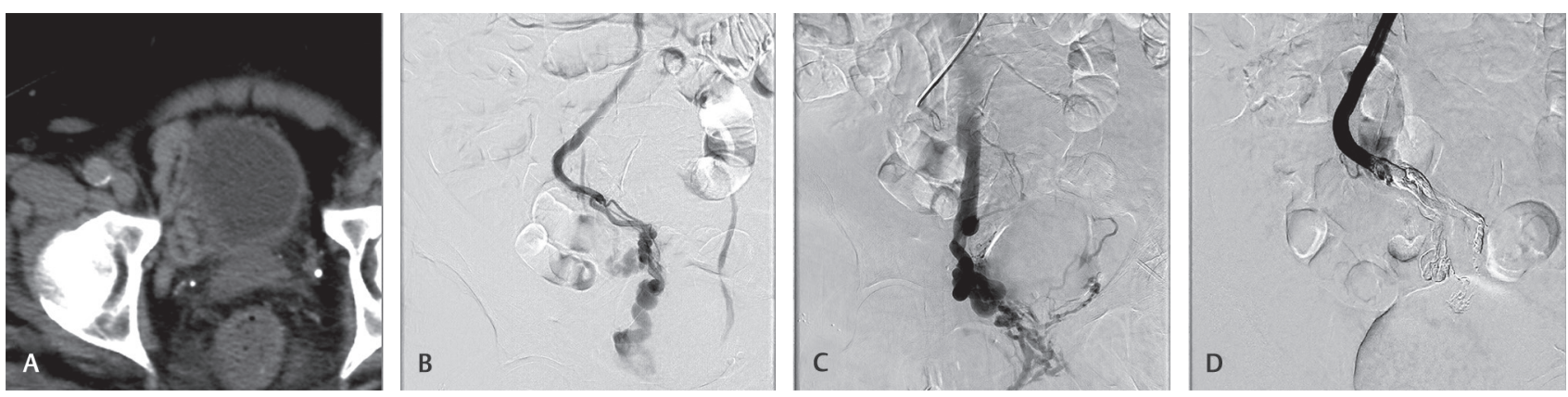

Fig. 5 (A) Computed tomography (CT) showing ileal varices. (B) Ileal varices from the superior mesenteric vein. (C) Systemic collateralization to internal iliac vein. (D) Postembolization state with Onyx 18. 


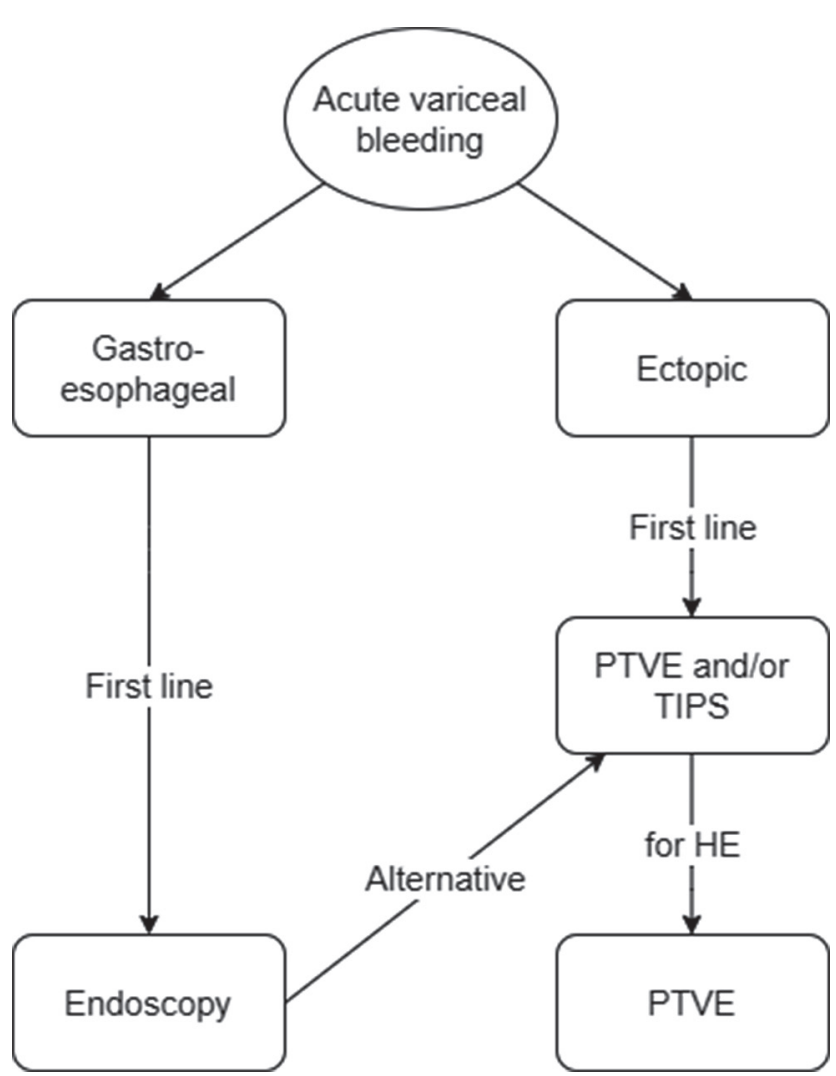

Fig. 6 An approach to the cirrhotic patient with acute variceal bleeding.
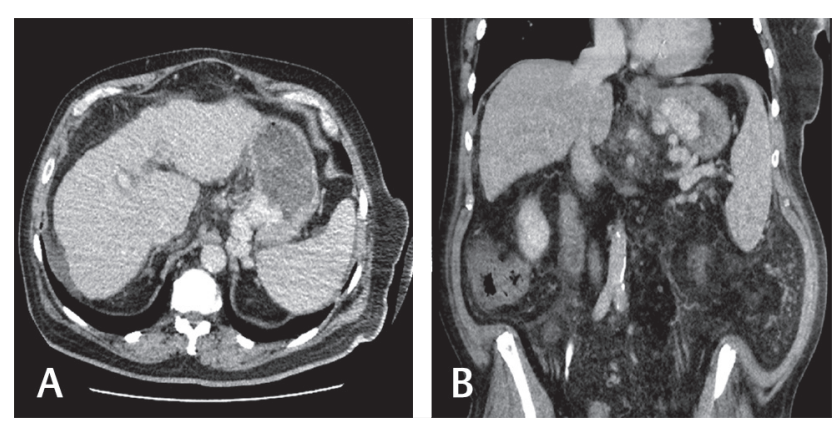

Fig. 7 Computed tomography (CT) of large gastric fundal varix: (A) Axial; (B) Coronal.

\section{Ectopic Varices}

While most literature concentrates on gastroesophageal variceal bleeding, we show that ectopic variceal bleeding can be just as important. In cases 4,5 , and 6 , we show that patients with ileal varices (from the superior mesenteric vein), rectal varices (from the inferior mesenteric vein), and umbilical varices (from a recanalized umbilical vein) respectively could be treated in an emergency setting with complete angiographic obliteration of varices and clinical hemostasis.

\section{Endoscopic Variceal Ligation}

Current endoscopic therapies such as variceal ligation only obliterate mucosal and submucosal varices, without any effect on feeding vessels. ${ }^{22}$ PTVE is advantageous in allowing for the embolization of a wider venous network, including feeding vessels. Zhang et $\mathrm{al}^{37}$ compared rates of variceal recurrence and rebleeding among groups of patients based on areas of venous embolization, and found these complications were lower in patients who had embolization of a more diverse venous network, specifically left gastric vein, vessels around the gastric fundus, and variceal lower esophageal veins. ${ }^{37}$ However, if the embolic material fails to reach the lower esophageal veins and instead gathers in the gastric cardia vessels, EVL would be required as adjunctive treatment.

Adjunctive EVL was in fact required for case 3 for rebleeding and also attempted for case 2 for prophylaxis. This combination therapy has also been shown to be effective in reducing variceal recurrence and rebleeding rates. ${ }^{22}$ Over 1 to 3 years' follow-up, our one case of rebleeding compares favorably with Wang et $\mathrm{al}^{20}{ }^{20}$ who found that only 4 out of 32 patients (12.5\%) developed rebleeding for PTVE (over a similar follow-up period), compared with 17 out of 45 for EVL. However, we also showed that in case 8, PTVE can be successful in controlling esophageal bleeding when bands from prior EVL become dislodged.

\section{Transjugular Intrahepatic Portosystemic Shunt}

Aside from PTVE, studies have shown that TIPS is also more effective than endoscopic therapy at treating uncontrolled variceal bleeding. Tian et $\mathrm{al},{ }^{38}$ however, completed a retrospective study comparing TIPS and PTVE, and they found that both procedures were comparable in preventing variceal rebleeding. However, PTVE offered statistically significant better survival rates of $96.7,72.0$, and $36 \%$ at 1,3 , and 5 years in patients with MELD scores greater than 18 . These numbers are comparable to our case series, which only had three cases of MELD scores > 18, with 100\% survival at 1 year, and 67\% at 2 years.

In our case series, PTVE was elected over TIPS by the treating clinicians for patients presenting with gastroesophageal variceal bleeding to reduce the risk of HE. Tian et $\mathrm{al}^{38}$ also showed a statistically significant lower incidence of HE in PTVE patients (16.67\%) compared with TIPS patients (58.14\%). This compares favorably to our case series where only one of our patients developed HE.

\section{Modern Embolic Materials (Cyanoacrylate and Onyx)}

The use of cyanoacrylate as an embolic material has been found to be effective in numerous recent studies. Extensive 2-octyl cyanoacrylate variceal obliteration of lower esophageal and paraesophageal varices, submucosal varices, and the adventitial plexus of the cardia and fundus has been demonstrated on CT and portal venography. ${ }^{37}$ Importantly, PTVE with cyanoacrylate simultaneously obliterates the feeding vessel (for example, the gastric vein), which means that concurrent gastric and cardiac varices are eradicated along with esophageal varices. This is unlike EVL, which can induce and aggravate concurrent gastric varices. This is partly due to the material being permanently retained in paraesophageal veins without a time-dependent decrease. ${ }^{21}$ Cyanoacrylate was used successfully in cases 2 , $4,6,7$, and 8 . In all cases, we diluted the embolic agent with 
lipiodol (see - Table 2 ) to delay polymerization time to reach a maximum number of varices. This is particularly useful in patients with slow flow in varices and in those without large draining vessels. ${ }^{37}$

In cases 1,3 , and 5 , we used the proprietary liquid embolic agent Onyx 18. This agent has been successfully used in neurovascular procedures, such as cerebral aneurysms and arteriovenous malformations. ${ }^{39}$ Recent research has also suggested its use in the gastrointestinal tract with a high success rate in vascular embolization. ${ }^{40}$ Our case series is the first to document the use of Onyx 18 as an embolic agent in a PTVE procedure for both gastroesophageal and ectopic varices.

\section{Limitations}

There are several limitations in our study. The most glaring is the relatively small number of cases, which limits the use of any meaningful quantitative statistical analyses. Furthermore, no defined protocol with a set timeframe for medium- to long-term follow-up was implemented. This is compounded by the inherent limitations of retrospective data collection, where two cases were lost to follow-up. Ideally, a large-scale, prospective study or randomized controlled trial with strict equal time to follow-up over a longer term should be performed.

\section{Conclusion}

Early results from our case series are consistent with the literature, showing that PTVE (using NBCA/Onyx 18 alone or in combination with coils) for management of uncontrolled variceal bleeding is a safe and effective treatment option. In line with recent studies, our case series also highlights favorable rates of recurrent variceal bleeding and HE of PTVE compared with both EVL and TIPS. We show that PTVE is particularly promising for treating ectopic varices (in addition to gastroesophageal) and when other methods such as TIPS, EVL, and BRTO are contraindicated or ineffective.

\section{Conflict of Interest}

None declared.

\section{References}

1 Pagliaro L, D'Amico G, Pasta L, et al. Portal hypertension in cirrhosis: natural history. In: Bosch J, Groszmann RJ, eds. Portal Hypertension: Pathophysiology and Treatment. Oxford, United Kingdom: Blackwell Scientific Publications; 1994

2 García-Pagán JC, Caca K, Bureau C, et al; Early TIPS (Transjugular Intrahepatic Portosystemic Shunt) Cooperative Study Group. Early use of TIPS in patients with cirrhosis and variceal bleeding. N Engl J Med 2010;362(25):2370-2379

3 Graham DY, Smith JL. The course of patients after variceal hemorrhage. Gastroenterology 1981;80(4):800-809

4 Garcia-Tsao G. Current management of the complications of cirrhosis and portal hypertension: variceal hemorrhage, ascites, and spontaneous bacterial peritonitis. Gastroenterology 2001;120(3):726-748

5 Bosch J, Abraldes JG, Groszmann R. Current management of portal hypertension. J Hepatol 2003;38(Suppl 1) :S54-S68
6 Burroughs AK, Vangeli M. Transjugular intrahepatic portosystemic shunt versus endoscopic therapy: randomized trials for secondary prophylaxis of variceal bleeding: an updated meta-analysis. Scand J Gastroenterol 2002;37(3):249-252

7 Papatheodoridis GV, Goulis J, Leandro G, Patch D, Burroughs AK. Transjugular intrahepatic portosystemic shunt compared with endoscopic treatment for prevention of variceal rebleeding: a meta-analysis. Hepatology 1999;30(3):612-622

8 Luca A, D’Amico G, La Galla R, Midiri M, Morabito A, Pagliaro L. TIPS for prevention of recurrent bleeding in patients with cirrhosis: meta-analysis of randomized clinical trials. Radiology 1999;212(2):411-421

9 Pomier-Layrargues G, Villeneuve JP, Deschênes M, et al. Transjugular intrahepatic portosystemic shunt (TIPS) versus endoscopic variceal ligation in the prevention of variceal rebleeding in patients with cirrhosis: a randomised trial. Gut 2001;48(3):390-396

10 Kanagawa H, Mima S, Kouyama H, Gotoh K, Uchida T, Okuda K. Treatment of gastric fundal varices by balloon-occluded retrograde transvenous obliteration. J Gastroenterol Hepatol 1996; 11(1):51-58

11 Kwak HS, Han YM. Percutaneous transportal sclerotherapy with N-butyl-2-cyanoacrylate for gastric varices: technique and clinical efficacy. Korean J Radiol 2008;9(6):526-533

12 Kiyosue H, Matsumoto S, Yamada Y, et al. Transportal intravariceal sclerotherapy with N-butyl-2-cyanoacrylate for gastric varices. J Vasc Interv Radiol 2004;15(5):505-509

13 Lunderquist A, Vang J. Transhepatic catheterization and obliteration of the coronary vein in patients with portal hypertension and esophageal varices. N Engl J Med 1974;291(13):646-649

14 Smith-Laing G, Scott J, Long RG, Dick R, Sherlock S. Role of percutaneous transhepatic obliteration of varices in the management of hemorrhage from gastroesophageal varices. Gastroenterology 1981;80(5 pt 1) :1031-1036

15 Lunderquist A, Börjesson B, Owman T, Bengmark S. Isobutyl 2-cyanoacrylate (bucrylate) in obliteration of gastric coronary vein and esophageal varices. AJR Am J Roentgenol 1978; 130(1):1-6

16 Benner KG, Keeffe EB, Keller FS, Rösch J. Clinical outcome after percutaneous transhepatic obliteration of esophageal varices. Gastroenterology 1983;85(1):146-153

17 Bengmark S, Börjesson B, Hoevels J, Joelsson B, Lunderquist A, Owman T. Obliteration of esophageal varices by PTP: a follow-up of 43 patients. Ann Surg 1979;190(4):549-554

18 L'Herminé C, Chastanet $\mathrm{P}$, Delemazure $\mathrm{O}$, Bonnière $\mathrm{PL}$, Durieu JP, Paris JC. Percutaneous transhepatic embolization of gastroesophageal varices: results in 400 patients. AJR Am J Roentgenol 1989;152(4):755-760

19 Toumeh KK, Girardot JD, Choo IW, Andrews JC, Cho KJ. Percutaneous transhepatic embolization as treatment for bleeding ileostomy varices. Cardiovasc Intervent Radiol 1995; 18(3):179-182

20 Wang J, Tian XG, Li Y, et al. Comparison of modified percutaneous transhepatic variceal embolization and endoscopic cyanoacrylate injection for gastric variceal rebleeding. World J Gastroenterol 2013;19(5):706-714

21 Sun A, Shi YJ, Xu ZD, et al. MDCT angiography to evaluate the therapeutic effect of PTVE for esophageal varices. World J Gastroenterol 2013;19(10):1563-1571

22 Bian S, Tian XG, Hu JH, Wang GC, Zhang CQ. Percutaneous transhepatic variceal embolization combined with endoscopic ligation for the prevention of variceal rebleeding. J Dig Dis 2013;14(7):388-395

23 Sarin SK, Lahoti D, Saxena SP, Murthy NS, Makwana UK. Prevalence, classification and natural history of gastric varices: a long-term follow-up study in 568 portal hypertension patients. Hepatology 1992;16(6):1343-1349 
24 Ryan BM, Stockbrugger RW, Ryan JM. A pathophysiologic, gastroenterologic, and radiologic approach to the management of gastric varices. Gastroenterology 2004;126(4):1175-1189

25 Sabri SS, Swee W, Turba UC, et al. Bleeding gastric varices obliteration with balloon-occluded retrograde transvenous obliteration using sodium tetradecyl sulfate foam. J Vasc Interv Radiol 2011;22(3):309-316, quiz 316

26 Jalan R, Hayes PC; British Society of Gastroenterology. UK guidelines on the management of variceal haemorrhage in cirrhotic patients. Gut 2000;46(Suppl 3-4):III1-III15

27 Chang MY, Kim MD, Kim T, et al. Plug-assisted retrograde transvenous obliteration for the treatment of gastric variceal Hemorrhage. Korean J Radiol 2016;17(2):230-238

28 Gwon DI, Kim YH, Ko GY, et al. Vascular plug-assisted retrograde transvenous obliteration for the treatment of gastric varices and hepatic encephalopathy: a prospective multicenter study. J Vasc Interv Radiol 2015;26(11):1589-1595

29 Cho SK, Shin SW, Lee IH, et al. Balloon-occluded retrograde transvenous obliteration of gastric varices: outcomes and complications in 49 patients. AJR Am J Roentgenol 2007;189(6):W365-W372

30 Ninoi T, Nishida N, Kaminou T, et al. Balloon-occluded retrograde transvenous obliteration of gastric varices with gastrorenal shunt: long-term follow-up in 78 patients. AJR Am J Roentgenol 2005;184(4):1340-1346

31 Tsurusaki M, Sugimoto K, Matsumoto S, et al. Bleeding duodenal varices successfully treated with balloon-occluded retrograde transvenous obliteration (B-RTO) assisted by CT during arterial portography. Cardiovasc Intervent Radiol 2006;29(6):1148-1151

32 Zamora CA, Sugimoto K, Tsurusaki M, et al. Endovascular obliteration of bleeding duodenal varices in patients with liver cirrhosis. Eur Radiol 2006;16(1):73-79
33 Hashimoto N, Akahoshi T, Yoshida D, et al. The efficacy of balloon-occluded retrograde transvenous obliteration on small intestinal variceal bleeding. Surgery 2010;148(1):145-150

34 Hayashi S, Baba Y, Senokuchi T, Ueno K, Nakajo M. Successful portal-systemic shunt occlusion of a direct shunt between the inferior mesenteric vein and inferior vena cava with balloon-occluded retrograde transvenous obliteration following recanalization after placing a covered stent in the portal and superior mesenteric veins. Jpn J Radiol 2009;27(4):180-184

35 Minami S, Okada K, Matsuo M, Kamohara Y, Sakamoto I, Kanematsu T. Treatment of bleeding stomal varices by balloonoccluded retrograde transvenous obliteration. J Gastroenterol 2007;42(1):91-95

36 Minamiguchi $\mathrm{H}$, Kawai N, Sato M, et al. Balloon occlusion retrograde transvenous obliteration for inferior mesenteric vein-systemic shunt.JVasc Interv Radiol 2011;22(7):1039-1044

37 Zhang CQ Liu FL, Liang B, et al. A modified percutaneous transhepatic variceal embolization with 2-octyl cyanoacrylate versus endoscopic ligation in esophageal variceal bleeding management: randomized controlled trial. Dig Dis Sci 2008;53(8):2258-2267

38 Tian X, Shi Y, Hu J, Wang G, Zhang C. Percutaneous transhepatic variceal embolization with cyanoacrylate vs. transjugular intrahepatic portal systematic shunt for esophageal variceal bleeding. Hepatol Int 2013;7(2):636-644

39 Loffroy RF, Abualsaud BA, Lin MD, Rao PP. Recent advances in endovascular techniques for management of acute nonvariceal upper gastrointestinal bleeding. World J Gastrointest Surg 2011;3(7):89-100

40 Lenhart M, Paetzel C, Sackmann M, et al. Superselective arterial embolisation with a liquid polyvinyl alcohol copolymer in patients with acute gastrointestinal haemorrhage. Eur Radiol 2010;20(8):1994-1999 